\title{
Semi-Empirical Method for Estimating Stiffness and Deformation of Cylindrical Retaining Diaphragm Wall
}

\author{
Jiequn ZHA*, Jian JIA, Xiaolin XIE
}

\begin{abstract}
This study presents a semi-empirical method to estimate stiffness and deformation of cylindrical retaining diaphragm wall. Based on the concept of "arch-beam" method, the retaining structure is separated into two structural components: arch unit and supported beam unit. The stiffness of both units is computed by parameter analytical method and then combined to obtain the total retaining stiffness of cylindrical diaphragm wall. The proposed model incorporates major factors considered in design of cylindrical retaining structure such as soil condition, geometry of excavation, geometries and materials of diaphragm wall, spacing and stiffness of ring beam, joints in diaphragm wall. A statistical equation is developed to relate the stiffness and lateral wall deformation. The proposed stiffness and deformation model is validated by 24 cylindrical excavation cases in literature.
\end{abstract}

Keywords: cylindrical retaining structure; diaphragm wall; parameter analytical method; stiffness

\section{INTRODUCTION}

The use of underground space has been increasingly recognized as an important part of urban development. However, creation of underground structure encounters many challenges. The settlements of adjacent ground surface and existing infrastructures caused by excavations have particular raised concerns from geotechnical engineering prospective. Such problems have been extensively studied [1-6]. The equations correlating the lateral deformation of retaining structure and induced settlement of adjacent ground surface have been established by those studies. Besides the in-situ soil condition and construction quality, the deformation of retaining structure is mainly affected by its stiffness. As such, some researchers such as Clough \& O'Rourke [1] and Bryson \& Zapata-Medina [5] have proposed several methods to estimate the stiffness of retaining structure.

In recent years, cylindrical retaining diaphragm wall has been utilized in the construction for various underground facilities such as anchorage foundations of bridges, underground storage tanks for oil and gas industry, underground substations, foundations of high-rise buildings, swirl pools, underground pump stations, and shafts for tunneling. A major advantage is that the arch effect created by cylindrical retaining wall and surrounding soil effectively creates a self-balancing system eliminating the struts or tie-back anchors. Meanwhile, excavation work can be accelerated by avoiding complicated construction coordination between the excavators and strut or anchor installers. Naturally, the load transfer mechanism of cylindrical diaphragm wall is different with conventional plane retaining structure which could be simplified as plane strain model. In horizontal direction, the external radial load of cylindrical diaphragm wall is transferred tangentially as normal compression in retaining wall by arch effect. In the vertical direction, the lateral load resists by bending moment of retaining wall and radial compression of supports. The supports are usually provided by ring beams or inner walls (not struts or tieback anchors). Therefore, the conventional stiffness computation methods $[1,5]$ for plane retaining structures are no longer applicable to cylindrical diaphragm wall.
Because of limited literature, the performance of cylindrical diaphragm wall has not been fully studied. Tan \& Wang [7] summarized the relationship between deformation and excavation diameter, based on 11 cylindrical excavation cases in Shanghai. Jia et al. [8] studied the relationship between deformation and hoop flexibility of 15 cases in different countries. However, neither the influence of ring beam support nor soil condition was considered in those studies. Because the mechanical analysis of cylindrical diaphragm wall is complicated, it is difficult for engineers to evaluate the stiffness of the structure in the design reasonably.

In this paper, a semi-empirical method for estimating stiffness and deformation of cylindrical retaining structure will be presented. The retaining structure is separated into arch unit and supported beam unit. The stiffness of both units is computed and then combined to obtain the total retaining stiffness. Based on the numerical analysis, the relationship between stiffness and deformation of cylindrical retaining structure is established. The proposed model will be evaluated by 24 cylindrical diaphragm wall cases.

\section{MECHANISM ANALYSIS \\ 2.1 Form of Total Stiffness}

The internal force of cylindrical diaphragm walls includes circumferential pressure and vertical bending moment. We adopted the concept of "arch-beam" method used in the arch dam design to separate cylindrical retaining structure into two structural components: horizontal arch unit and vertical supported beam unit. The lateral load is assumed to be divided between two units, and the deformations of two units at each conjugated points in all parts of the structure must agree with each other. Fig. 1a plots a typical cylindrical retaining structure consisting of cylindrical diaphragm wall braced by ring beams. The retaining structure and surrounding soil can be simplified as a plane strain model as shown in Fig. 1b. The outer soil is simplified as lateral earth pressure. The ring beams are idealized as springs. The inner soil below excavation surface also provides supports to diaphragm wall by passive earth pressure. As such, we idealize the inner soil as soil springs. In tangential direction, the arch effect in the 
cylindrical diaphragm wall is represented by tangential wall springs on the model slice.

Based on the concept of "arch-beam" method, the retaining structure model in Fig. $1 \mathrm{~b}$ could be separated into arch unit and supported beam unit as shown in Figs. 2a and $2 b$. The stiffness of arch unit is essentially equivalent to the tangential compression stiffness of wall springs as shown in Fig. 2a. The stiffness of supporting beam unit is combination of vertical bending stiffness of retaining wall, radial compression stiffness of ring beams and inner soil. The mechanical characteristics of each unit will be analyzed by Finite Element Method in the following sections.

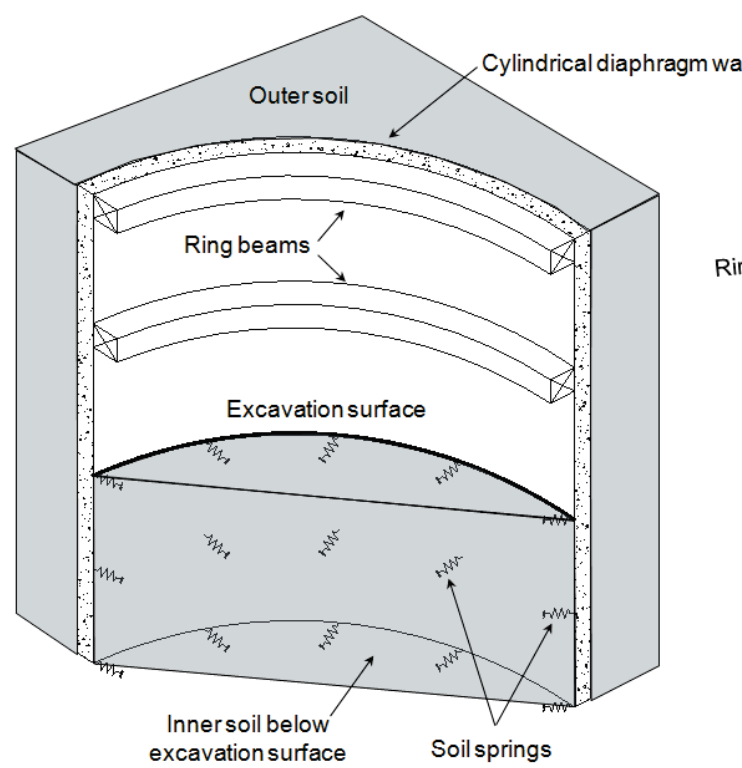

(a) Consisting of cylindrical diaphragm wall

Consisting of cylindrical diaphragm wall
Figure 1 Consisting and plane strain model of cylindrical retaining structure

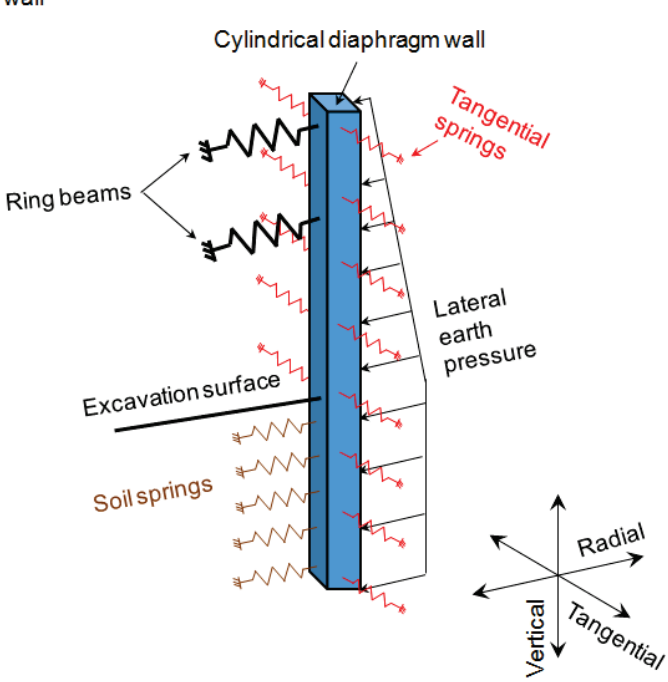

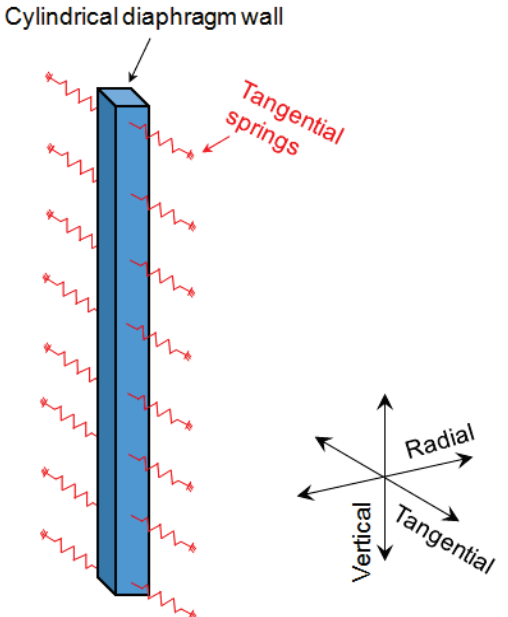

(a) Arch unit

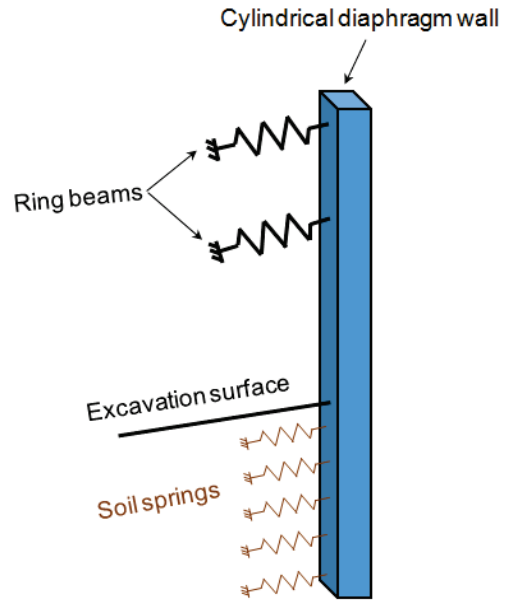

(b) Supported beam unit

Figure 2 The stiffness components of cylindrical retaining structure

The parameters $K_{h}$ and $K_{v}$ are introduced here to represent the stiffness of arch unit and supported beam unit, respectively. Actually, $K_{v}$ represents the stiffness of conventional plane retaining structures. In some special cases, the arch unit and supported beam unit can work independently. For example, when the radius tends to be infinite, the cylindrical diaphragm walls could be treated as the conventional plane retaining structure, $K_{h}$ tends to be 0 , and only $K_{v}$ would provide bearing capacity. For another case, if the lateral pressure is evenly distributed along the hoop and longitudinal directions, and no ring beams and soil spring exist, then the structure would only be uniformly compressed and deformed, and only arch beam unit could provide bearing capacity. Therefore, $K_{h}$ and $K_{v}$ should be independent of each other, and the total stiffness of cylindrical diaphragm walls $K$ could be expressed as:

$$
K=K_{h}+K_{v}
$$

Here, the units of $K, K_{h}$ and $K_{v}$ are $\mathrm{MPa}$.

\subsection{Numerical Model}

Numerical studies are performed in a Finite Element Method (FEM) code ANSYS to obtain the stiffness of cylindrical diaphragm wall. Generally, the $R$ of cylindrical diaphragm wall is much larger than $b_{w}$, element SHELL63 which could bear both in-plane and normal loads is used to simulate the diaphragm wall 
structure. Element BEAM188 which can be well applied to large deflection analysis is used to simulate the ring beams. The generated cylindrical retaining structure model is shown in Fig. 3a. Because this study mainly focuses on the stiffness and deformation of retaining structure, the surrounding soils are simplified in the model. The outer soils are simplified as the lateral distributed loads: at rest earth pressure above excavation surface and constant earth pressure below the excavation surface as shown in Fig. 3b. The inner soils are simulated by LINK10 element, which can be set to withstand only compression and not tension. Such simplifications also eliminate difficulties of soil constitutive model selection and corresponding model parameters determination. (a)

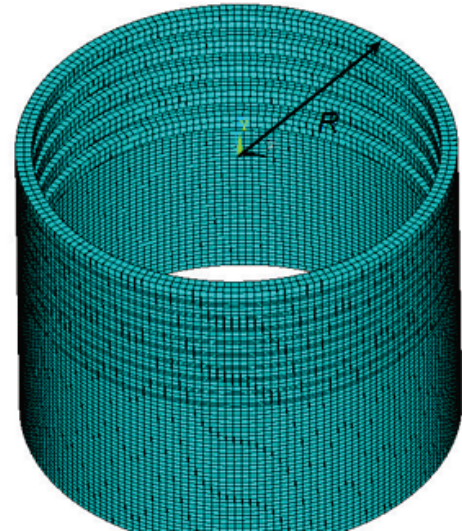

(b)

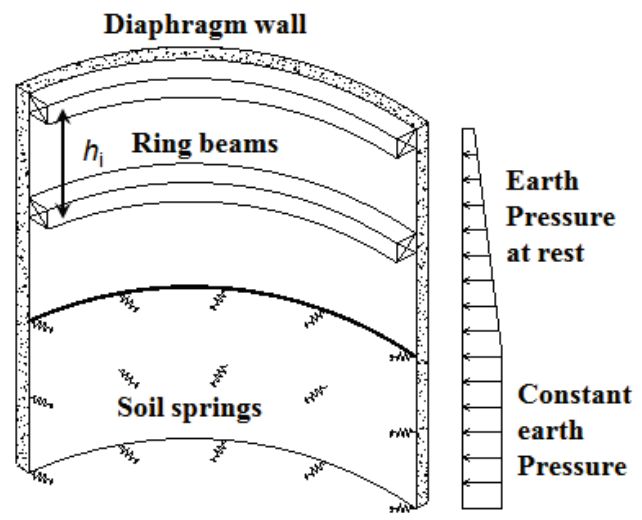

Figure 3 FEM model of Cylindrical excavation

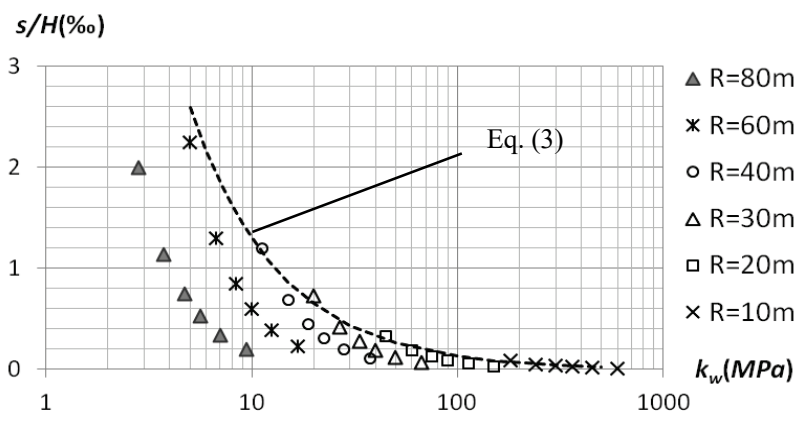

(a)

$H=30 \mathrm{~m}, k_{s}=0.6 \mathrm{MPa}, b_{w}=0.6 / 0.8 / 1.0 / 1.2 / 1.5 / 2.0 \mathrm{~m}$ $\mathrm{s} / H(\%)$

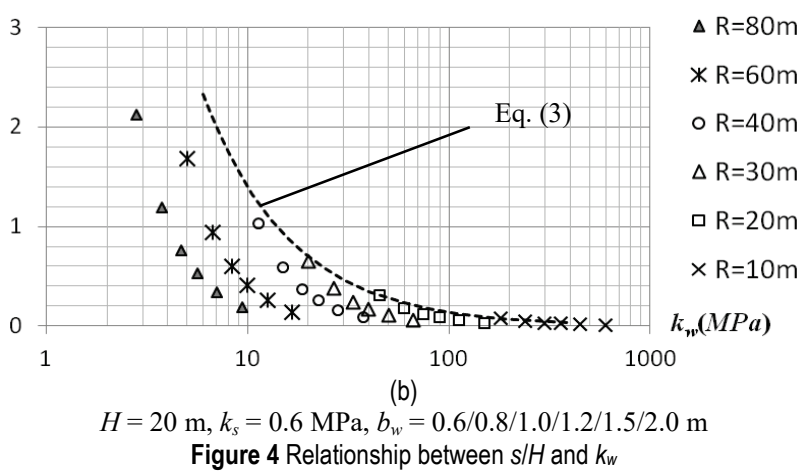

Total 256 combinations of parameters $R, b_{w}, H$ and $k_{s}$ are considered in the simulations as listed in Tab.1. Here, $R$ and $b_{w}$ is radius and thickness of diaphragm wall. $k_{s}$ is stiffness of soil springs, which can also be called the reaction coefficient of foundation soil. The values of $k_{s}$ in Tab. 1 covered the soil spring stiffness from muddy clay to dense sand. $H$ is excavation depth.

Table 1 Parameters of FEM models

\begin{tabular}{|c|c|c|}
\hline Wall radius & $R / \mathrm{m}$ & $10,20,30,40,60,80$ \\
\hline Excavation depth & $H / \mathrm{m}$ & 20,30 \\
\hline Wall thickness & $b_{w} / \mathrm{m}$ & $0.6,0.8,1.0,1.2,1.5,2.0$ \\
\hline Soil spring stiffness & $k_{s} / \mathrm{MPa}$ & $3,6,9,18$ \\
\hline The spacing of ring beam & $H / \mathrm{m}$ & $3,5,6,10$ \\
\hline
\end{tabular}

The Young's modulus of the retaining wall and ring beams $\left(E_{w}\right.$ and $\left.E_{c}\right)$ are both set as $30000 \mathrm{MPa}$ which is equal to the Young's modulus of concrete. The length of diaphragm wall is $1.7 \mathrm{H}$. The area of each ring beam $A_{c}$ is $2.5 \mathrm{~m}^{2}$. The unit weight of soil $\gamma$ is $18 \mathrm{kN} / \mathrm{m}^{3}$ and coefficient of earth pressure $K_{0}$ is 0.72 .

\section{DETERMINING THE STIFFNESS OF CYLINDRICAL DIAPHRAGM WALL}

\subsection{Stiffness of Arch Unit}

According to the mechanical relationship, the tangential compression stiffness of cylindrical diaphragm wall, also called hoop stiffness, is computed as:

$k_{w}=\frac{E_{w} A_{w}}{R^{2}}$

where $A_{w}$ is cross section area of diaphragm wall per unit length.

The maximum lateral deformation of diaphragm wall $s$ is computed from the FEM model. Parameters $b_{w}$ and $R$ are in accordance with the range shown in Tab. 1, while other parameters are constant. The relationship between lateral deformation ratio $s / H$ and $k_{w}$ is shown in Fig. 4. Lateral deformation decreases rapidly as $k_{w}$ increases. The curve cluster composed of $s / H$ and $k_{w}$ is roughly a power function relationship. When $R \leq 20 \mathrm{~m}$, the relationship could be expressed approximately as:

$\frac{s}{H}=\frac{q_{1}}{H k_{w}}$

where $q_{1}$ is the constant earth pressure as shown in Fig. 3. It can be concluded that $k_{w}$ plays a dominant role in total stiffness of cylindrical diaphragm wall with small radius. However, as $R>20 \mathrm{~m}$, the deformation ratio $s / H$ is located below the curve of Eq. (3). The role of $k_{w}$ gradually weakens with the increase of $R$. It suggests that influence 
of other parameters on total stiffness increased for cylindrical diaphragm wall with large radius.

The diaphragm wall is not an isotropic solid but consists of series of panels connected by joints. As such, the hoop stiffness of diaphragm wall will be reduced to some extent depending on the types of joints and their construction qualities. To quantify such effect, a reduction factor $\alpha$ is introduced into hoop stiffness [9-11]:

$K_{h}=\alpha k_{w}=\alpha \frac{E_{w} b_{w}}{R^{2}}$

where $K_{h}$ is the stiffness of arch unit. Based on the studies of Schwamb [12], Chen et al. [13] and Zhai et al. [11], $\alpha$ is suggested as $0.9 \sim 1.0$ for cylindrical diaphragm walls with cutter joints, $0.5 \sim 0.6$ for steel joint walls and $0.25 \sim 0.3$ for stop-end tube joint walls.

\subsection{Stiffness of Supported Beam Unit}

Generally, the stiffness of supported beam unit $K_{v}$ is related to wall thickness $b_{w}$, spacing of ring beam $h$, hoop stiffness of ring beam $k_{c q}$, and soil spring stiffness $k_{s}$. The parameter analytical method is used to study the form of $K_{v}$. Here, the hoop stiffness of ring beam could be expressed as:

$k_{c q}=\frac{E_{c} A_{c}}{R_{c}^{2}}$

where $E_{c}, R_{c}$ is the Young's modulus and radius of ring beam.

The relationship between deformation ratio $s / H$ and parameters $k_{c q}, k_{s}, h$ and $b_{w}$ are shown in Figs. 5 to 8 , respectively. The curve cluster composed of $s / H$ and parameters $b_{w}, k_{c q}$ and $k_{s}$ are roughly power functions. The relationship between $s / H$ and $h$ is approximately a linear function. The fitting relationship of $s / H$ is related to a function expressed as $f\left(b_{w}^{-2}, k_{s}^{-0.5}, k_{c q}^{-0.5}, h\right)$ approximately. Based on parameter fitting method, the stiffness of supported beam unit is proposed as:

$$
K_{v}=\frac{15}{l_{1}} \frac{b_{w}^{2}}{h} \frac{1}{\left(\frac{1}{\sqrt{k_{c q}}}+\frac{1}{\sqrt{k_{s}}}\right)^{2}}
$$

where $l_{1}$ is unit length. For conventional plane retaining structures, lateral wall deformation consists of wall deflection caused by the vertical bending and displacement caused by compression of support and inner soil. In Eq. (6), $b_{w}^{2} / h$ represents vertical bending resistance of diaphragm wall, $k_{c q}$ and $k_{s}$ represent compression resistance of support and inner soil. As $K_{v}$ is not related to $R$, the stiffness of supported beam unit is important for cylindrical diaphragm wall with large radius.

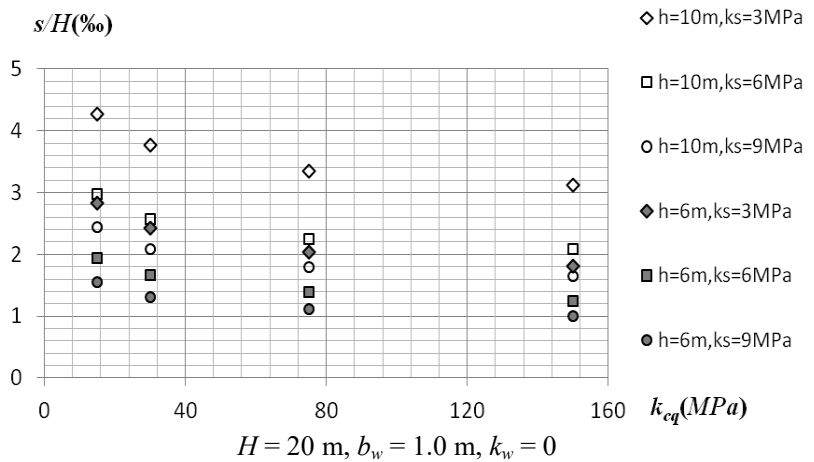

Figure 5 Relationship between $s / H$ and $k_{c q}$
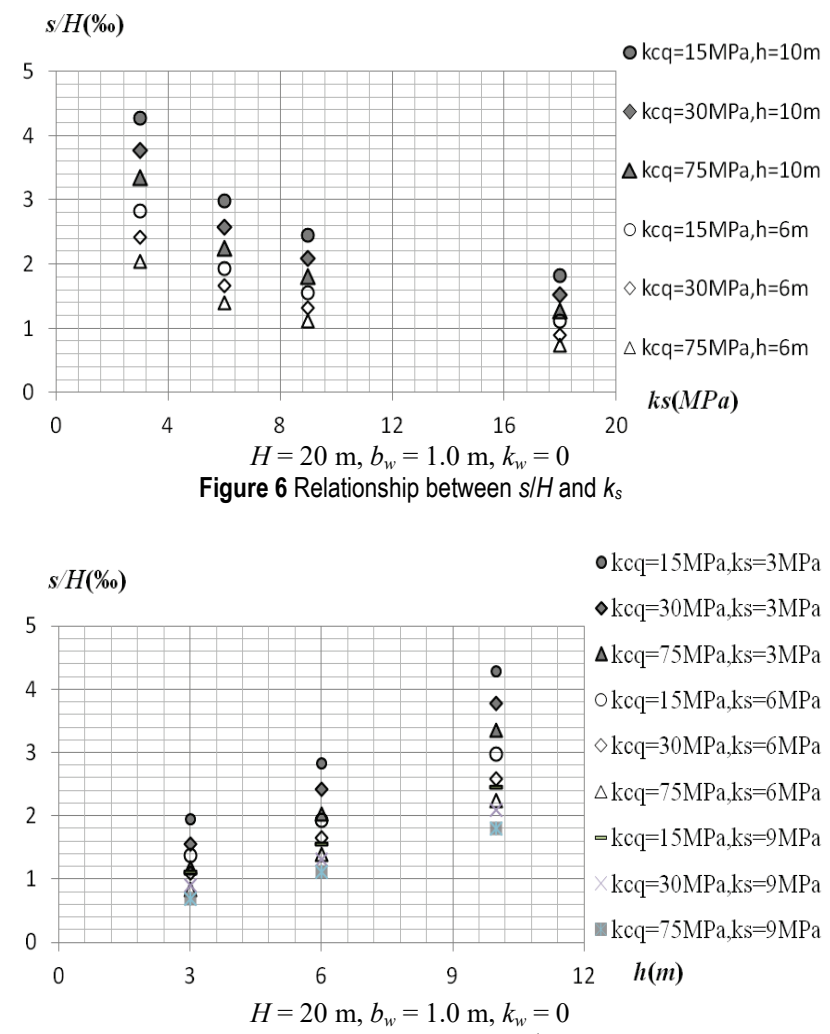

Figure 7 Relationship between $s / H$ and $h$

$s / H(\%)$

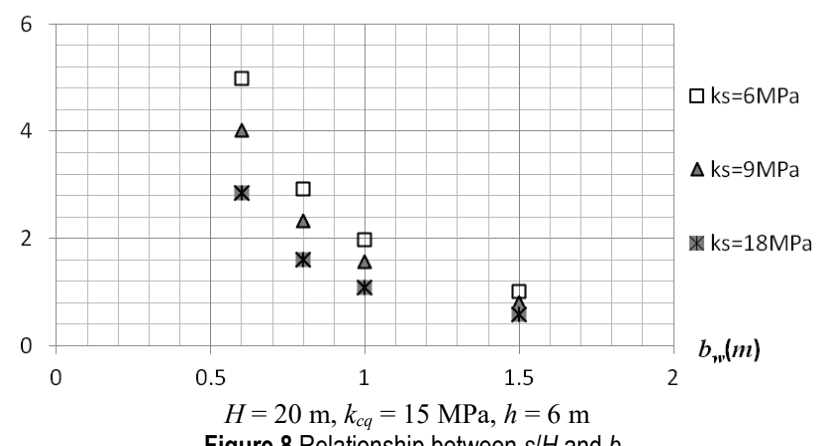

Figure 8 Relationship between $s / H$ and $b_{w}$

\subsection{Total Stiffness of Cylindrical Retaining Structure}

The total stiffness of the cylindrical retaining structure is the stiffness combination of arch unit and supported beam unit: 
$K=\alpha \frac{E_{w} A_{w}}{R^{2}}+\frac{15}{l_{1}} \frac{b_{w}^{2}}{h}\left(\frac{1}{\sqrt{k_{c q}}}+\frac{1}{\sqrt{k_{s}}}\right)^{-2}$

Eq. (7) incorporates the effects of the in-situ soil property, radius and depth of excavation, thicknesses of cylindrical diaphragm wall, spacing and stiffness of bracing system, and the type of joints. Verified by 256 sets of parameter combinations, the relationship between $s / H$ and $K$ is shown in Fig. 9. As can be seen $K$ and $s / H$ have a power function relationship approximately, and the lateral deformation ratio could be computed as:

$\frac{s}{H}=\frac{q_{1}}{K}=\frac{K_{0} \gamma+\frac{q_{0}}{H}}{K}$

Based on data regression analysis, the determination coefficient of Eq. (8) is 0.91. The curve of Eq. (8) is consistent with the calculated results.

Eqs. (7) and (8) dictate the relative importance of various factors on the deformation of cylindrical retaining structures. Considering soil condition and excavation geometries are usually unchangeable prerequisites, the parameters $b_{w}, h$ and $k_{c q}$ become important to design a cylindrical retaining diaphragm wall. However, because ring beam should be constructed after excavation, therefore the wall would deform before $k_{c q}$ play a role in stiffness at each excavation step. Ring beam can only limit wall deformation caused by subsequent excavation. In terms of controlling deformation, the effect of increasing $k_{c q}$ is not as good as the effect of increasing $b_{w}$. A rule of thumb is to increase wall thickness $b_{w}$, which affects stiffness of both units. Additionally, enhancing the arch effect of cylindrical diaphragm wall by improving the construction quality, such as ensuring the verticality and continuity of trench and improving the joint quality between panels, can also effectively increase the stiffness and thus decrease deformation of cylindrical retaining structure.

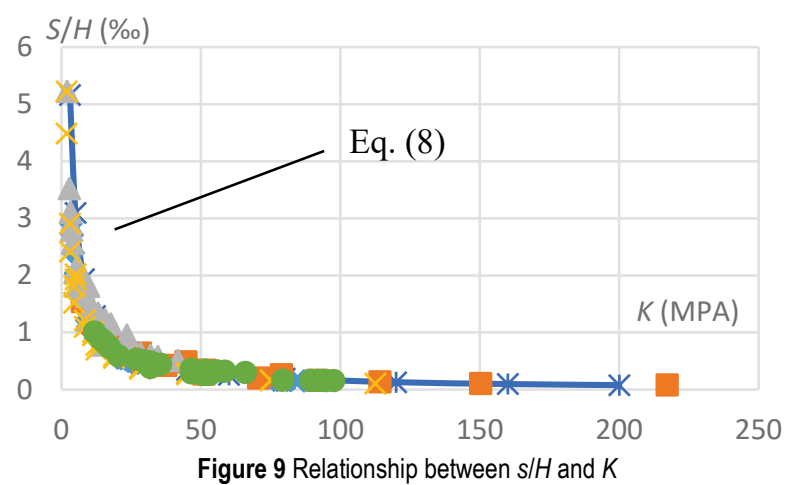

\section{ASSESSMENT OF $K$}

Cylindrical retaining diaphragm wall has been applied in many projects. Tab. 2 collects 24 cylindrical excavation cases with various construction purposes, locations, soil conditions, diameters, and design parameters.

Table 2 Cases of Cylindrical Retaining Structures

\begin{tabular}{|c|c|c|c|c|c|c|c|c|}
\hline & & & & & & & & \\
\hline Case & $R / \mathrm{m}$ & $H / \mathrm{m}$ & $b_{w} / \mathrm{m}$ & $h_{i} / \mathrm{m}$ & $S / \mathrm{mm}$ & $\bar{s} / \mathrm{mm}$ & $\varphi /{ }^{\circ}$ & Reference \\
\hline S1 & 28.3 & 27 & 1.5 & 14 & $2 \sim 10$ & 6 & $22^{*}$ & Cabarkapa et al. [9] \\
\hline $\mathrm{S} 2$ & 70 & 27 & 1.8 & 27 & $25 \sim 35$ & 30 & 32 & Chen and Hung [14] \\
\hline $\mathrm{S} 3$ & 40.3 & 63.5 & 2.2 & 5 & $9 \sim 11$ & 10 & 30 & Furuya et al. [15] \\
\hline S4 & 61 & 31 & 1.2 & 5.2 & $45 \sim 90$ & 68 & 19.8 & Jia et al. [8] \\
\hline S5 & 39 & 55.4 & 1.7 & 55.4 & $7 \sim 19$ & 13 & $36^{*}$ & Kim and Lee [16] \\
\hline S6 & 72 & 29.2 & 2.4 & 4.2 & $13 \sim 18$ & 15 & $19^{*}$ & Kumagai et al. [17] \\
\hline S7 & 50 & 14 & 1 & 14 & $10 \sim 16$ & 14 & 28 & Li et al.[18] \\
\hline S8 & 25 & 16 & 1 & 3.6 & $15 \sim 25$ & 18 & 18 & Liu et al.[19] \\
\hline S9 & 35 & 43 & 1.5 & 5 & $10 \sim 26$ & 18 & 27.5 & Xu et al. [20] \\
\hline $\mathrm{S} 10$ & 23.15 & 14.7 & 0.8 & 14.7 & $4 \sim 6$ & 5 & 30 & Marten and Bourgeois [21] \\
\hline S11 & 8.15 & 50.8 & 1 & 8.5 & 2 & 2 & $20^{*}$ & Morita et al. [22] \\
\hline $\mathrm{S} 12$ & 16 & 35 & 1 & 5 & 18.7 & 18.7 & 17.8 & Ning et al. [23] \\
\hline S13 & 15 & 65 & 1.2 & 8 & 10 & 10 & $19^{*}$ & Parashar et al.[24] \\
\hline S14 & 18.5 & 68.3 & 1.2 & 8.4 & 10 & 10 & $19^{*}$ & Parashar et al.[24] \\
\hline S15 & 13.5 & 33 & 1 & 5 & 4 & 4 & 13.8 & Qu and Zhou [25] \\
\hline S16 & 14.45 & 71 & 1.2 & 71 & $3.5 \sim 4$ & 4 & 33 & Schwamb [12] \\
\hline S17 & 25 & 11 & 1 & 4 & $13 \sim 15$ & 14 & 16.1 & Sun et al. [26] \\
\hline S18 & 50 & 18 & 1 & 4.5 & $25 \sim 35$ & 30 & 15.7 & Tan and Wang [7]; Tan and Wang [27] \\
\hline S19 & 40 & 49.6 & 1.4 & $5^{\#}$ & 15 & 15 & 30 & Takagi et al. [28] \\
\hline $\mathrm{S} 20$ & 35.9 & 25.5 & 1.2 & 3.2 & $9 \sim 11$ & 10 & 21 & Wang et al. [29] \\
\hline $\mathrm{S} 21$ & 65 & 34 & 1.2 & 4.85 & $30 \sim 47$ & 39 & 18.5 & Wang et al. [30] \\
\hline $\mathrm{S} 22$ & 42.5 & 18 & 1 & 6 & $10 \sim 40$ & 25 & 19 & Win et al. [31] \\
\hline S23 & 7 & 28 & 1 & 28 & 2.2 & 2.2 & 25 & Wu et al.[32] \\
\hline S24 & 30.3 & 26.45 & 0.8 & 4 & 10.6 & 10.6 & 34 & Zhou and Luo [33] \\
\hline
\end{tabular}

Due to the large variability of designs, it is necessary to establish the following criteria to determine the parameters in Tab. 2:

1. The $s$ in Tab. 2 are the recorded maximum lateral wall deformations, which vary in a range with different monitoring locations. Therefore, the average of $s$ is used as deformation of retaining structure represented by $\bar{s}$.

2 . Some design parameters are not directly provided by original studies. We estimated those parameters based on the comparisons to the similar projects. Those values are denoted by superscripts "\#".

3. The coefficient of earth pressure is calculated by $K_{0}$ $=1-\sin \varphi$. Some studies described in-situ soil conditions but did not directly provide $\varphi$. We estimated their $\varphi$ based on the given soil descriptions. Those $\varphi$ are distinguished by superscripts "*".

The computed $K$ by Eq. (7) and monitored $s / H$ of those cases are plotted in Fig. 10. Clearly $s / H$ decreases with 
increasing $K$. The curve of Eq. (8) is also plotted in Fig. 10 for comparison. The Eq. (8) agrees well with computed $K$ and reported deformations. Lateral deformation of cylindrical diaphragm walls can be estimated conveniently by Eq. (8).

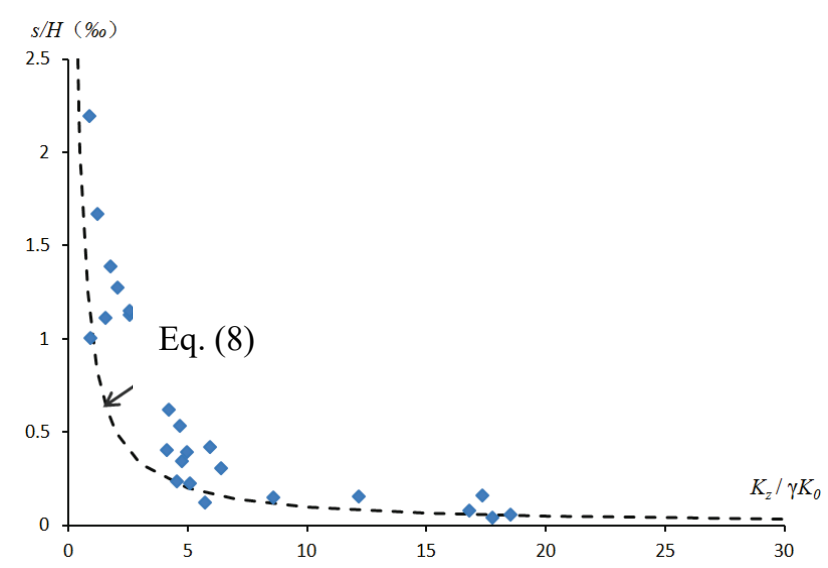

Figure 10 Statistics of lateral wall deformation of cylindrical retaining diaphragm wall

For excavations in urban area, controlling the deformation of retaining structure to minimize the effects to surrounding buildings or structures is always the primary consideration in design. As such, lateral wall deformation $s / H$ is usually determined based on the allowable deformation of surrounding environment at first. Then the proposed Eq. (8) can be used to compute the required $K$. In the next step, Eq. (7) can be used to determine the various design parameters of retaining structure to satisfy previously established stiffness $K$.

\section{DISCUSSION AND CONCLUSIONS}

A semi-empirical method is proposed to compute the stiffness and deformation of cylindrical retaining structure in this study. The proposed method agrees well with the reported data of 24 cases from literature. The following conclusions are made:

1) The proposed stiffness and deformation computation method of cylindrical retaining structure can effectively incorporate various parameters involved in design such as diameter and thickness of diaphragm wall, the stiffness of bracing system, the excavation depth at each step, and soil property.

2) When radius is less than $20 \mathrm{~m}$, the total stiffness of cylindrical retaining wall mainly depends on that of arch unit. The stiffness of supported beam unit is important for cylindrical retaining wall with large radius.

3) Besides the in-situ soil and diameter of excavation, the thickness of cylindrical diaphragm wall is critical to total stiffness. Therefore, choosing an appropriate wall thickness is important in design.

4) The joints in diaphragm wall are also important for controlling the deformation of cylindrical diaphragm wall. The cutter joints are recommended by present study; they generally generate smaller deformation than the stop-end joints and steel joints do.

5) As retaining wall always deforms before ring beam plays a role in stiffness at each excavation step, increasing the stiffness of ring beam can only reduce wall deformation to a certain extent.
Besides stiffness, the deformation of retaining structure is also affected by secondary factors related to construction such as the construction quality (including verticality and continuity), the surcharges around retaining wall, excessive excavation, the ground reinforcement, dewatering and drainage, and exposure time before being braced. Further studies are still needed to evaluate effects of those factors on stiffness and deformation of retaining structure.

\section{REFERENCES}

[1] Clough, G. W. \& O'Rourke, T. D. (1990). Construction induced movements of in situ walls. Design and Performance of Earth Retaining Structures, 439-470.

[2] Long, M. (2001). Database for retaining wall and ground movements due to deep excavations. Journal of Geotechnical \& Geoenvironmental Engineering, 127(3), 203-224. https://doi.org/10.1061/(ASCE)1090-0241(2001)127:3(203)

[3] Moormann, C. (2004). Analysis of wall and ground movements due to deep excavations in soft soil based on a new worldwide database. Jpn Geotech Soc Soils Found, 44(1), 87-98. https://doi.org/10.3208/sandf.44.87

[4] Kung, G. T., Juang, C. H., Hsiao, E. C. et al. (2007). Simplified model for wall deflection and ground-surface settlement caused by braced excavation in clays. Journal of Geotechnical \& Geoenvironmental Engineering, 133(6), 731-747. https://doi.org/10.1061/(ASCE)1090-0241(2007)133:6(731)

[5] Bryson, L. S. \& Zapata-Medina, D. G. (2011). Method for estimating system stiffness for excavation support walls. Journal of Geotechnical \& Geoenvironmental Engineering, 138(9), 1104-1115. https://doi.org/10.1061/(ASCE)GT.1943-5606.0000683

[6] Zhai, J. Q., Jia, J., \& Xie, X. L. (2014). Study on Deformation Due to Deep Excavation Based on Monitoring Data in Soft Soil Area in Shanghai. Tunneling and Underground Construction, 237-245. https://doi.org/10.1061/9780784413449.024

[7] Tan, Y. \& Wang, D. L. (2013). Characteristics of a largescale deep foundation pit excavated by the central-island technique in Shanghai soft clay. I: bottom-up construction of the central cylindrical shaft. Journal of Geotechnical \& Geoenvironmental Engineering, 139(11), 1875-1893. https://doi.org/10.1061/(ASCE)GT.1943-5606.0000928

[8] Jia, J., Zhai, J. Q., Li, M. G. et al. (2019). Performance of Large-Diameter Cylindrical Diaphragm Walls in a Deep Excavation: Case Study of Shanghai Tower. Journal of Aerospace Engineering, 32(5), 04019078. https://doi.org/10.1061/(ASCE)AS.1943-5525.0001056

[9] Cabarkapa, Z., Milligan, G. W. E., Menkiti, C. O. et al. (2003). Design and performance of a large diameter shaft in Dublin Boulder Clay. British Geotechnical Association International Conference on Foundations, Dundee, Thomas Telford, 175-185.

[10] Zdravkovic, L., Potts, D. M., \& St John, H. D. (2005). Modeling of a $3 \mathrm{D}$ excavation in finite element analysis. Geotechnique, 55(7), 497-513. https://doi.org/10.1680/geot.2005.55.7.497

[11] Zhai, J. Q., Xie, X. L., \& Jia, J. (2010). Research and Analysis method in Large-deep Cylindrical Diaphragm Wall of Shanghai Tower. Chinese Journal of Geotechnical Engineering, 32(Supp.1), 392-396.

[12] Schwamb, T. (2014). Performance monitoring and numerical modelling of a deep Cylindrical excavation. Doctoral dissertation, University of Cambridge.

[13] Chen, F. Q., Yang, G. H., Zhang, Y. C. et al. (2012). Discussion on value of coefficient in structural design of 
circular diaphragm wall. Chinese Journal of Geotechnical Engineering, 34(S0), 203-206.

[14] Chen, J. \& Hung, C. (2007). Design and Construction of the Underground Circle MRT-station in Downtown. Tunnel Construction, S2, 486-493.

[15] Furuya, N., Yamaoka, R., \& Paulson Jr., B. C. (1994). Construction of Akashi-Kaikyo Brige West Anchorage. Journal of Construction Engineering \& Management, 120(2), 337-356. https://doi.org/10.1061/(ASCE)0733-9364(1994)120:2(337)

[16] Kim, D. S. \& Lee, B. C. (2005). Instrumentation and Numerical Analysis of Cylindrical Diaphragm Wall Movement during Deep Excavation at Coastal Area. Marine Georesources and Geotechnology, 23(1-2), 117-136. https://doi.org/10.1080/10641190590953728

[17] Kumagai, T., Ariizumi, K., \& Kashiwagi, A. (1999). Behaviour and Analysis of a Large-Scale Cylindrical Earth Retaining Structure. Soils and Foundations, 39(3), 13-26. https://doi.org/10.3208/sandf.39.3_13

[18] Li, Y., Li, H. M., Wu, H. et al. (2011). Study on Design Method of Great Cylindrical Foundation Pits. Chinese Journal of Underground Space and Engineering, 7(5), 938944.

[19] Liu, C. Y., Cai, W. H., Zhao, Z. B. T. et al. (2008). Construction monitoring and analysis of a Cylindrical diaphragm retaining wall. Chinese Journal of Geotechnical Engineering, 30(Supp), 447-451.

[20] Xu, P. F., Hu, X. Y., Wang, M. H. et al. (2015). Mechanical Behaviors of Cylindrical Retaining Structures in Ultra-Deep. Innovative Materials and Design for Sustainable Transportation Infrastructure, 229-243. https://doi.org/10.1061/9780784479278.022

[21] Marten, S. \& Bourgeois, E. (2005). Three-dimensional behavior of a Cylindrical excavation in Nantes, France. Preprint Proc. $5^{\text {th }}$ IS Geotechnical Aspects of Underground Construction in Soft Ground Amsterdam, 69-74 https://doi.org/10.1201/NOE0415391245.ch120

[22] Morita, Y., Amano, A., Takahashi, H. et al. (1988). Construction of Extra-Deep Cylindrical Vertical Shaft in Reclaimed Ground by the Diaphragm Wall and Inverted Lining Method. Proceedings of JSCE, (397), 187-195. https://doi.org/10.2208/jscej.1988.397_187

[23] Ning, Z .W., Xie, X. Y., \& Huang, H. W. (2007). Analysis of Monitoring Data of a Cylindrical Whirlpool Foundation Pit. Chinese Journal of Underground Space and Engineering, 3(8), 1391-1396.

[24] Parashar, S., Mitchell, R., Hee, M. W. et al. (2007). Performance Monitoring of Deep Shafts at Changi WRP Project, Singapore. $7^{\text {th }} F M G M$ Field Measurements in Geomechanics, 1-12. https://doi.org/10.1061/40940(307)15

[25] Qu, J. T. \& Zhou, J. (2004). 3-Dimensional Numerical Analysis in a Very Deep Circle Pit. Journal of Kunming University of Science and Technology, 29(5), 96-99.

[26] Sun, W. H., Pei, C. Y., \& Shao, X. (2006). Analysis of Cylindrical Foundation Pit Diaphragm Wall Support Structure Monitoring Results. Construction Technology, 35(11), 15-18

[27] Tan, Y. \& Wang, D. L. (2015). Structural behaviors of large underground earth-retaining systems in Shanghai. I: Unpropped Cylindrical diaphragm wall. Journal of Performance of Constructed Facilities, 29(2), 040140581 14. https://doi.org/10.1061/(ASCE)CF.1943-5509.0000521

[28] Takagi, K., Maeda, T., Miyanaga, M. et al. (1999). A Study on the Behavior of Large-Scale Cylindrical Diaphragm-Wall in Sedimentary Soft Rock Area. Proceedings of JSCE, (630), 1-10. https://doi.org/10.2208/jscej.1999.630_1

[29] Wang, K., Zhang, T. K., \& Chen, S. C. (2014). Force and Deformation Analysis of the Retain Structure for Anchorage Foundation Pit of Huangpu Suspension Bridge over
Zhujiang River. Journal of Southwest University (Natural Science Edition), 32(7), 133-138.

[30] Wang, W. D., Zhu, W. L., Chen, Z. et al. (2008). Design, Study and Practice of Deep Cylindrical Excavation of Shanghai World Expro 500kv Underground Transmission Substation Project. Chinese Journal of Geotechnical Engineering, 30(Supp), 564-576.

[31] Win, E. S. A., Soh, S. S., \& Terzaghi, S. (2014). Field Performance of Triple Configured Cylindrical Diaphragm Wall. Underground Singapore.

[32] Wu, C. F., An, H. C., \& Li, F. Z. (2013). Analysis of the Mechanical and Deformation Characteristics of a Cylindrical Diaphragm Wall. Electronic Journal of Geotechnical Engineering, 18, 4979-4996.

[33] Zhou, J. \& Luo, X. B. (2003). Structural computation of cylindrical retaining structure using method of equivalent retaining of arch effect. Rock and Soil Mechanics, 24(2), 169-172.

\section{Contact information}

Jiequn ZHAI, Senior Engineer

(Corresponding author)

Tongji Architectural Design (Group) Co. Ltd.,

Shanghai, China

E-mail: tongjizjq@163.com

Jian JIA, Professor of Engineer

Tongji Architectural Design (Group) Co. Ltd.

Shanghai, China

Xiaolin XIE, Senior Enginee

Tongji Architectural Design (Group) Co. Ltd.

Shanghai, China 